
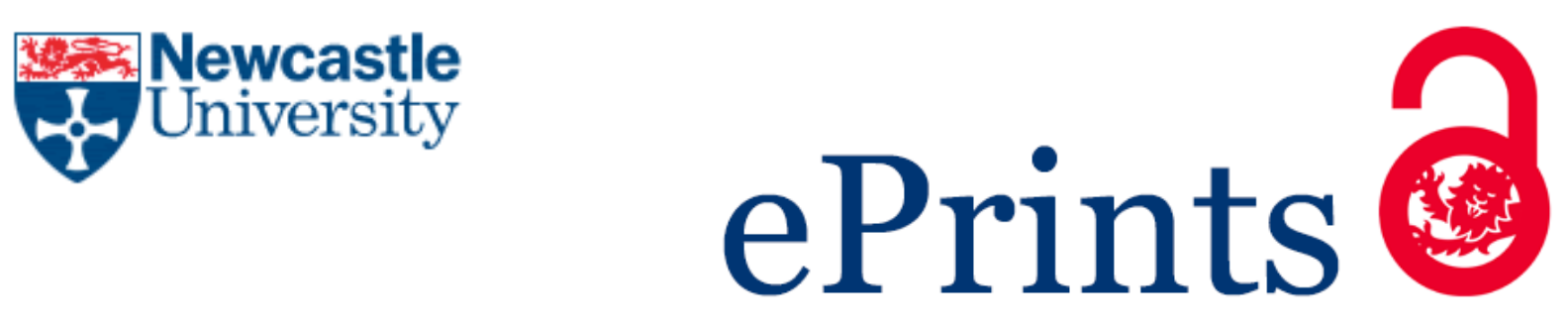

Williams R, Gillespie SM, Elliott IA, Eldridge H.

Characteristics of female solo and female co-offenders and male solo sexual

offenders against children.

Sexual Abuse: A Journal of Research and Treatment 2017, https://doi.org/10.1177/1079063217724767

\title{
Copyright:
}

This is an Accepted Manuscript of an article published by Sage Publications Ltd. In Sexual Abuse: A Journal of Research and Treatment on 09/09/2017, available online: https://doi.org/10.1177/1079063217724767

Date deposited:

$01 / 08 / 2017$

Embargo release date:

09 September 2018

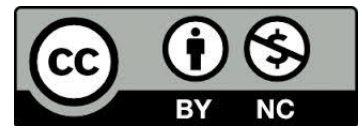

This work is licensed under a Creative Commons Attribution-NonCommercial 3.0 Unported License 
Title: Characteristics of female solo and female co-offenders and male solo sexual offenders against children

Running title: Characteristics of female and male sexual offenders

Authors: Rebecca Williams ${ }^{1 *}$, Steven M. Gillespie ${ }^{2,3}$, Ian A. Elliott ${ }^{4}$, Hilary J. Eldridge ${ }^{3,5}$

${ }^{1}$ North London Forensic Service, Barnet, Enfield and Haringey Mental Health NHS Trust, London, UK

${ }^{2}$ School of Psychology, Newcastle University, Newcastle, UK

${ }^{3}$ The Lucy Faithfull Foundation, Birmingham, UK

${ }^{4}$ Institute of Psychology, Health, and Society, University of Liverpool, Liverpool, UK

${ }^{5}$ School of Psychology, University of Birmingham, Birmingham, UK

This paper was accepted for publication in Sexual Abuse on $4^{\text {th }}$ July 2017.

This is the accepted version of the manuscript.

*Corresponding author: Dr Rebecca Williams, North London Forensic Service, Camlet 1,

Chase Farm Hospital, EN2 8JL, UK

E-mail: rebecca-williams@hotmail.co.uk 


\begin{abstract}
Studies have highlighted differences in the victim choice, offender and offense characteristics of female and male sexual offenders. However, little is known about how solo and cooffending females differ from solo male sexual offenders. We compared the characteristics of 20 solo and 20 co-offending females (co-offended with a male and/or female accomplice), and 40 male sexual offenders against children. We found that solo female offenders showed the most evidence of personal problems, including depression and sexual dissatisfaction. Compared with male offenders, female co-offenders showed poorer self-management, but better sexual self-regulation. Male offenders had a greater history of offending and showed more evidence of sexual abuse supportive cognitions relative to both solo and co-offending females. These results are consistent with the need for a gender specific approach to working with sexual offenders, and may have implications for understanding the often complex treatment needs of these clients.
\end{abstract}

Key words: Female sexual offenders, male sexual offenders, solo offenders, co offenders, child sexual abuse 


\section{Characteristics of female solo and female co-offenders and male solo sexual offenders against children}

\section{A gender informed approach to sexual offending}

The assessment and treatment needs of female sexual offenders (FSOs) remain relatively poorly understood compared with those of their male counterparts (Cortoni, 2010). Professionals working with male sexual offenders (MSOs) can draw upon a broad research literature, empirically validated risk assessment instruments, and a knowledge base of 'what works ' in assessment and treatment (Cortoni, 2010). However, the assessment and treatment needs of FSOs and MSOs are likely to differ, and considerable caution has been urged in applying MSO theory and knowledge to FSOs. Numerous authors have emphasized the need for a gender specific approach to working with sexual offenders (Ford, 2010; Gannon \& Alleyne, 2013; Gannon, Rose \& Cortoni, 2010). This approach should be informed by a good understanding of how FSOs and MSOs differ, as well as an understanding of different subtypes of both female and male sexual offenders.

The need for a greater understanding of female sexual offending is highlighted by the results of a recent meta-analysis which showed that the proportion of sexual offenders who are female is higher than first thought (Cortoni, Babchishin, \& Rat, 2016). Characteristics of FSOs include female specific offense supportive cognitions, early victimization, and periods of severe sexual, violent, and emotional abuse (Gannon \& Cortoni, 2010). During adulthood, FSOs present with sexual and/or physical victimization (Gannon, Rose, \& Ward, 2008; Turner, Miller \& Henderson, 2008; Wijkman, Bijleveld, \& Hendriks, 2010), personality disorder, mental illness, and drug and alcohol use (Miller, Turner, \& Henderson, 2009; Muskens et al., 2011; Turner et al., 2008; Strickland, 2008; Wijkman et al., 2010), 
relationship problems, intimacy deficits, and sexual abuse supportive cognitions (Gannon et al., 2008; Grayston \& De Luca, 1999; Nathan \& Ward, 2002). Notably, several, if not all of these factors represent known treatment targets for MSOs. However, few studies have undertaken a direct comparison of FSOs and MSOs.

\section{Female and male sexual offenders}

Studies comparing FSOs and MSOs have documented several similarities as well as differences in terms of victim choice, offender, and offense characteristics. In a retrospective case file analysis of alleged FSOs and MSOs, FSOs reported more abusive experiences during childhood, including physical, sexual, and emotional abuse, and were more likely to report having been the victim of adult intimate partner violence (West, Friedman, \& Kim, 2011). However, these findings are limited by small sample sizes, and a reliance on case file reviews of alleged, rather than convicted or admitting offenders. A larger scale comparison of FSOs and MSOs was carried out by Freeman and Sandler (2008), who compared the case files of 390 FSOs and 390 MSOs from the New York State sex offender registry. Group differences were predominantly related to criminal histories and victim characteristics, and MSOs showed a greater number of previous sexual and non-sexual convictions compared with FSOs, and were also more likely to have offended against females (Freeman \& Sandler, 2008). Although low levels of sexual recidivism hampered comparisons relating to sexual reoffending at re-arrest, both groups displayed similar factors relating to re-arrests for nonsexual offenses. It was concluded that although risk factors for female and male sexual offending may be similar, a broader range of characteristics should be examined in future research.

As well as comparisons of victim choice and offence characteristics, others have examined differences in the personal characteristics of FSOs and MSOs. When features of 
psychopathology were compared between 128 FSOs and 136 MSOs referred for treatment in the U.S., females' self-reports indicated higher levels of psychopathology, with descriptive statistics indicating elevated scores across anxiety, depression, schizophrenia, and borderline features (Miller et al., 2009). Furthermore, a Latent Profile Analysis (LPA) revealed four distinct classes of offenders: moderate defensiveness, elevated drug and alcohol use, moderate psychopathology, and extensive psychopathology. FSOs were more likely than MSOs to be in the extensive and moderate psychopathology classes, while MSOs were better classified according to defensiveness/impression management, and drug and alcohol use (Miller et al., 2009). While these findings are informative, they may reflect biases in how FSOs and MSOs are dealt with following sexual offenses. For example, it has been suggested that while females may be more likely to be viewed as having mental health problems, MSOs may be more likely to enter the criminal justice system (West et al., 2011).

More recently, Williams and Bierie (2015) reported on a much larger sample using the National Incident-Based Reporting System, comparing FSOs and MSOs on 802,150 incidents of sexual assault. Both groups tended to offend more often in their homes, were likely to be acquainted with their victims, and rarely used drugs/alcohol or injured the victims during the offense. However, key differences also emerged, and showed that FSOs were more likely to commit their offense with a male accomplice, and were more likely to offend against their own children. MSOs on the other hand were more likely to offend against their step-children (Williams \& Bierie, 2015). Consistent with earlier studies, both MSOs and FSOs were more likely to offend against victims of the opposite sex, although this was more pronounced among MSOs. The finding that females more often offended with a male accomplice supports a growing body of literature distinguishing between female solo and co-offenders, and represents an important point of heterogeneity among FSOs. 


\section{Solo and co-offending females}

Typological frameworks suggest that offending alone (solo offender), versus offending with an accomplice (co-offender), represents an important distinguishing feature of FSOs. A 'male coerced' category of FSOs was first recognized by Mathews, Matthews, and Speltz (1989), and was later developed by Nathan and Ward (2001) to distinguish between compliant victim, rejected/revengeful, and willing/ally co-offender relationships. These types of female co-offender may sow distinct motivations to offend, including high levels of dependency on males, or feelings of being rejected by the child, or a male partner in favor of the child (Nathan \& Ward, 2011). Despite increasing recognition of the solo versus co-offender distinction, little is known about how these distinct subtypes compare with males who sexually offend against children.

Compared with solo offenders, a greater proportion of females who co-offend with a male partner have been shown to be 'specialists' rather than 'once only' or 'generalist' offenders. While specialists typically commit multiple sexual offenses, but few other, typically minor non-sexual offenses, generalists are more versatile, committing many other minor, as well as more serious non-sexual offenses (Wijkman, Bijleveld, \& Hendriks, 2011). Other findings have shown that although solo and co-offending females did not differ in terms of age, ethnicity, location, or type of offense, co-offenders were more likely than solo-offenders to have multiple victims, familial victims, male and female victims, and previous convictions for non-sexual offenses (Vandiver, 2006). These results are consistent with the finding that FSOs who offend alone are more likely to have an unrelated or a male victim, while cooffenders are more likely to have a female victim (Muskens, Bogaerts, van Casteren, \& Labrijn, 2011). However, it should also be considered that the victim choice of co-offenders 
might better reflect the sexual interests of the male co-offender, rather than the female herself.

In terms of their clinical characteristics, solo relative to co-offenders are more likely to have received a diagnosis of a DSM-IV (American Psychiatric Association, 1994) Axis I disorder, or a mood disorder in particular (Muskens et al., 2011). Also, a more recent study comparing 20 solo and 20 co-offenders across a range of clinical characteristics found that the environmental niche of solo offenders was better characterized by a history of mental health and substance abuse difficulties compared with that of co-offenders (Gillespie, Williams, Elliott, Eldridge, Ashfield, \& Beech, 2015). Furthermore, solo offenders reported more negative mood states and abusive fantasies during the time preceding their offense, while cooffenders more often reported having current partners who were known sex offenders, and other involvement with known offenders (Gillespie et al., 2015).

In a more comprehensive analysis of FSO types, 47, 287 incidents of female perpetrated sexual offenses were categorized in to one of four groups: solo offenders, female-male pairs, an all-female group consisting of females who offended with another female, and a multiple perpetrator group formed of females who offended with three or more other offenders (Budd, Bierie, \& Williams, 2015). Females with a male accomplice were more likely than solo females to have offended against female victims, dependent children, and against a victim within their family. It was also noted that while the solo and all female groups shared similar characteristics, female-male pairs appeared more similar to the multiple perpetrator group. However, incidents were not distinguished between on victim age, and included both offenses against children, and adults. Given that important differences exist between male offenders who prefer child versus adult victims (Ahlmeyer, Kleinsasser, Stoner, \& Retzlaff, 2003; Langton \& Marshall, 2001), the results of Budd et al. (2015) should be applied with caution to understanding females who have offended solely against children. 


\section{Sexual abuse supportive cognitions in females}

The presence of a male co-offender has also been linked with the types of sexual abuse supportive cognitions held by FSOs (Beech, Parrett, Ward, \& Fisher, 2009; Gannon, Hoare, Rose, \& Parrett, 2010). This work has focussed upon the presence or absence of implicit theories identified by Ward (2000) referring to Children as sexual (views that children can be sexual beings who are able to consent); Dangerous world (the world is a dangerous and threatening place); Nature of harm (views that some sexual behaviour is acceptable and minimising the harm that their offending behaviour has caused); Uncontrollability (views of the world as being uncontrollable and believing that things can just occur); and Entitlement (believing that people are entitled to have their needs met by others). Beech et al. (2009) suggest that these distortions, with the exception of entitlement, can be identified among FSOs, and may vary between FSO subtypes. Furthermore, Gannon et al. (2010) argue that the offense supportive cognitions of FSOs may be considered gender specific, and often include reference to men as controlling the actions of women, female abuse not as harmful, men as threatening, and partners' needs are more important than victims. However, gender specific cognitions are not consistently identified among FSOs, and do not reliably vary between solo and co-offenders (Gannon \& Alleyne, 2013; Gillespie et al., 2015).

\section{The present study}

Although several studies have sought to compare FSOs and MSOs, these studies have typically focused on victim choice and offense characteristics, or failed to compare across a range of offender characteristics. In addition, inconsistencies have been identified in the extent to which the offense supportive cognitions of FSOs appear similar to those held by MSOs, and the extent to which these attitudes vary between FSO subtypes. Finally, studies comparing FSOs and MSOs using statistical methods have failed to distinguish between 
subtypes of FSO, despite increasing evidence that the presence or absence of a co-offender represents an important distinguishing feature of this group (Gillespie et al, 2015; Muskens et al., 2011; Vandiver, 2006).

In the present study, we aimed to compare the offender characteristics of three different groups of individuals who had sexually offended against children: female solo offenders $(n=$ $20)$, female co-offenders $(n=20)$, and male solo offenders $(n=40)$. For the purposes of clarity, when referring to these groups in the present study, the terms solo offender and cooffender refer to solo offending females, and co-offending females (co-offended with a male and/or female accomplice), respectively. The term male sexual offenders (and its abbreviation MSOs) refers to solo male sexual offenders. We used the Assessment Guidance Framework for use with Women who Sexually Abuse Children: Version 2.0 (Gillespie et al., 2015), referred to as The Framework, to code for developmental factors, including early childhood abuse and parental relationships; psychological dispositions, including selfregulation and sexual abuse supportive cognitions; environmental niche factors (see Ward \& Beech, 2006); personal and environmental offense preceding factors; and positive factors that might protect against sexual offending and support treatment progress.

We hypothesized that the three groups would be distinguishable on several factors. In particular, we hypothesized that solo FSOs and solo MSOs would appear more similar, and would be distinguishable from co-offenders on various factors related to the motivations for sexual offending. These included poor sexual self-regulation, problematic interpersonal functioning, and negative affective states. Similarly, we hypothesized that MSOs relative to co-offenders would show more evidence of sexual abuse supportive cognitions relating to a preference and entitlement to sex with children. We made no specific predictions regarding the cognitions of solo and co-offending females given inconsistent findings in this area. 


\section{Method}

\section{Design}

We used The Framework to code for the presence or absence of the following characteristics: (a) developmental factors, (b) psychological dispositions, (c) environmental niche factors, (d) offense preceding factors, and (e) positive factors which may support the offender in making positive changes. We also coded each case for the presence or absence of sexual abuse supportive cognitions, and compared the presence or absence of these between solo and coFSOs, and MSOs. The study design was approved by the University of Birmingham Science, Technology, Engineering, and Mathematics (STEM) Ethical Review Committee. All procedures adhered to British Psychological Society research guidelines.

\section{Participants}

The sample consisted of 40 FSOs and 40 MSOs referred to the Lucy Faithfull Foundation (LFF), UK, through the criminal justice or child protection systems in the UK. Participants were included if they met the following criteria: aged 18 years or older at the time of the offense; offended against a person or persons under the age of 16; had either been convicted of the offense in a criminal court, had a judge's finding of fact against them in a family court, or had admitted to the offense. All of the participants in the sample were referred to the LFF for assessment and/or intervention purposes. Based on the inclusion criteria specified, LFF practitioners identified a list of suitable files relating to individuals who they had previously assessed. This list was then used to guide file selection. These files were subject to an additional review before scoring to ensure that sufficient detail was reported to be coded using The Framework, and to ensure a good match to the inclusion criteria. Where additional files were needed, the researchers were provided access to alternative files that were randomly selected and checked against inclusion criteria. 
Females were categorized as either solo or co-offenders based on file information that provided details of their offending behavior. Participants categorized as solo offenders had committed the sexual offense independently of another person or persons. The offending behaviors of females categorized as co-offenders took place in the presence of another person or persons over the age of 18 . None of the females in this sample had acted as both a solo offender and a co-offender, and none of the male participants had offended with a cooffender of either gender. Case file information indicated that $45 \%$ of female co-offenders were psychologically and/or physically coerced by their co-offender to engage in the sexual abuse of their victim.

Details of the participant's offenses are detailed in Table 1. Offenses are defined according to the criminal charge recorded in the case file. Note that some offenders had been charged with more than one offense type. Table 1 also provides additional information including offender, victim choice, and offense characteristics.

\section{INSERT TABLE 1 ABOUT HERE}

\section{The Framework}

Based on the analysis of 43 FSO case files, structured using the etiological model of risk (Beech \& Ward, 2004), and the protective factors outlined by Carr (1999), Elliott et al. (2010) identified a number of female-specific assessment and treatment items. These items formed the content of Version 1 of The Framework, which was later modified and updated by Gillespie et al. (2015) to create Version 2.0. Here we further modified Version 2.0 by removing all female specific items (e.g., males viewed as threatening) so that all items could be coded when using female files and male files. The majority of female-specific items that were removed from The Framework appeared under the sexual abuse supportive cognitions subscale of the psychological dispositions scale. 
It is important to stress that the items contained within The Framework are not considered to be "criminogenic" needs, since criminogenic needs are defined as "factors that, when changed, are associated with changes in the probability of recidivism" (Andrews \& Bonta, 2010, p. 49). Similarly, The Framework is not intended as a risk assessment tool. Instead, it is intended as a guide for clinical case formulation. Case formulation is typically described as a coherent set of factors that appear to be functionally associated with the cognitive, affective, and behavioral issues with which the client is presenting (e.g., Beck, 1995; Greenberger \& Padesky, 1995; Linehan, 1993; Muran \& Segal, 1992; Persons, 1993). Thus, the items listed represent exemplars of functional variables that have been found to be relevant in a relatively substantial sample of clinical cases.

The Framework contains five primary scales: Developmental factors, Psychological dispositions, Environmental niche factors, Offense preceding factors, and Positive factors. The Developmental factors scale contains six subscales which assess an offender's early life experiences and the presence of negative parental relationships, negative childhood environment, experiences of early emotional, violent, or sexual abuse, and other negative developmental factors.

The Psychological dispositions scale contains subscales which assess an offender's psychological functioning and well-being through items that tap interpersonal factors, selfmanagement/self-regulation, sexual self-regulation, and sexual abuse supportive cognitions. The interpersonal scale incorporates items indicating difficulties interacting with others, including the presence of low self-esteem and assertiveness. The self-management/selfregulation subscale contains items that focus on the individual's ability to effectively manage their emotions, as well as the presence of behavioural and emotional instability. The sexual self-regulation subscale includes items that identify a pre-occupation with sex and limited understanding of sex. This subscale also pays attention to any behaviours that indicate a 
deviant sexual interest such as evidence of grooming, the use of indecent images, and sadomasochistic practices. The sexual abuse supportive cognitions subscale is made up of several subscales referring to cognitions identified by Ward (2000): children as sexual beings, nature of harm, entitlement, uncontrollability, and dangerous world. A further 'other directedness' subscale was included to incorporate four categories of schemas (abandonment, emotional deprivation, defectiveness/shame, and social isolation), identified by Young (1990). It is argued by Beech et al. (2009) that these four schema-theory concepts may account for aspects of FSOs sexual abuse supportive cognitions, specifically those relating to coercion and striving to meet the needs of their co-offender.

The Environmental niche factors scale measures the presence of factors that can increase an individual's vulnerability to sexual offending, and that can influence and be influenced by an individual's environment (Ward \& Beech, 2006). Subscales assess distal personal factors (e.g., diagnosis of a mental illness, substance abuse, and depression), offence history, relationship problems (e.g., evidence of current relationship instability, and evidence of previous abusive relationships), family problems (e.g., instability, and local authority family involvement), and proximal factors (e.g., associating with antisocial peers, and being in an abusive relationship).

The Offence-preceding factors scale assesses the presence of different factors that immediately preceded the offending behavior. This scale contains a personal subscale that measures negative mood states, need for power/dominance, and need for intimacy, and an environmental subscale that examines factors including current partners are known sex offenders, and involvement with known offenders.

The Positive factors scale measures the presence or absence of factors that would support an individual to make positive changes and avoid re-offending. This scale includes four 
subscales assessing personal and contextual issues, treatment readiness, and mechanisms that may support an individual's treatment progress.

For each case file, each item of The Framework was scored as present or absent, keyed ' 1 ' and ' 0 ' respectively. Item present totals were calculated for each subscale.

\section{Procedure}

Access to anonymized case files of FSOs and MSOs was provided by the LFF, a UK based charitable organization that works with offenders and victims of child sexual abuse. The offenders had been referred to the LFF between 1994 and 2013 for assessment and/or intervention purposes. Information regarding whether an individual had offended on their own or as a co-offender was contained within each case file. All case files remained on LFF premises throughout data collection and were scored on-site in a private room. The information contained within the files consistently included a clinical assessment and/or intervention report written by an LFF practitioner. Other information contained within the files frequently included a combination of the following documents: (1) a psychometric report - this would typically contain information about the client's responses on a variety of self-report psychological measures of cognitive distortions, self-esteem, emotional loneliness, personality difficulties, victim empathy, and emotion regulation; and (2) other reports written by professionals from external organizations (e.g., probation officers or social workers).

Included files were identified as containing sufficient information to code the items of The Framework. This included sufficient information about the individual's offense and exploration of the offense by the practitioner. The files that were included contained a thorough analysis of historical events, events occurring immediately prior to and at the time of the offense, witness and police information, and the practitioner's formulation of the offense. Reports also included information about how the client reported feeling before and 
after the offense, and the motivations for committing the offence. Screening each file for sufficient detail meant that this information was available to be coded in a consistent manner across participants. The information was used to code each item in The Framework as present or absent. Where there was any doubt as to the presence or absence of an item, then that item was coded as absent.

The Framework was completed for each file by a trainee forensic psychologist with experience of working with female offenders. In addition, $20 \%$ of the files (eight female and eight male) were also coded by an experienced researcher for the purposes of establishing inter-rater reliability. We calculated Intra-class Correlation Coefficients (ICC) to establish consistency between the two raters for the total score, as well as for scores on each of the five primary scales. We also calculated a further ICC for the sexual abuse supportive cognitions subscale of the Psychological dispositions scale (see Table 2).

\section{INSERT TABLE 2 ABOUT HERE}

\section{Results}

Scores were calculated for each participant by summing the number of items in each subscale that were scored as present. To test the hypothesis that the characteristics of solo and coFSOs and MSOs would differ, we conducted a multivariate analysis of variance (MANOVA) for each of the five primary scales, including each individual subscale. A further MANOVA was used to test for differences in the sexual abuse supportive cognitions of solo and coFSOs, and MSOs, using scores on the sexual abuse supportive cognitions subscale of the psychological dispositions scale. Table 3 contains the means and standard deviations $(S D)$ for solo and co- FSOs, and MSOs, on each of the five primary scales, and the associated subscales. Table 3 also contains the results of the statistical analyses, including $F$ and $p$ values, and the partial-eta squared $\left(\mathrm{p} \eta^{2}\right)$ estimate of effect size. Estimates of effect size may 
be interpreted using the following suggested norms: small $=.01$, medium $=.06$, and large $=$ .14 (Cohen, 1988).

\section{Characteristics of solo and co-FSOs, and MSOs}

Overall, there was a significant difference between the groups on the Psychological dispositions (Pillai's Trace $\left.=.29, F(8,150)=3.161, p=.002, \mathrm{p}^{2}=.14\right)$; Environmental niche factors $\left(\right.$ Pillai's Trace $\left.=.53, F(10,148)=5.384, p<.001, \mathrm{p}^{2}=.27\right)$; Offense preceding factors (Pillai's Trace $=.31, F(4,154)=7.128, p<.001, \mathrm{p}^{2}=.16$ ); and Positive factors scales (Pillai's Trace $\left.=.42, F(8,150)=4.905, p<.001, \mathrm{p}^{2}=.21\right)$. The effect of group was not significant for the Developmental factors scale (Pillai's Trace $=.21, F(12,146)=$ $\left.1.404, p=.170, \mathrm{p}^{2}=.10\right)$. For each subscale of the Psychological dispositions, Environmental niche factors, Offense preceding factors, and Positive factors scales, where the three offender groups were found to differ, Games-Howell post-hoc tests were used to probe the nature of the difference between the three groups (see Table 3).

\section{INSERT TABLE 3 ABOUT HERE}

Psychological dispositions. Solo FSOs were found to score significantly higher than MSOs on the Interpersonal subscale. This indicates that female solo offenders were more likely to have reported low self-esteem, low assertiveness, and emotional loneliness/social isolation. Co- FSOs were found to score significantly higher than MSOs on the Selfmanagement/Self-regulation subscale, indicating higher levels of impulsivity, and an inability to cope with negative emotions among co-offending females. However, MSOs scored significantly higher than co- FSOs on the Sexual interest/Self-regulation subscale, indicating a greater tendency toward viewing the child as an ideal sexual partner, and showing more sadistic/humiliation elements to the abuse. 
Environmental niche factors. Scores on the Personal (distal) subscale were higher among solo FSOs compared with both co- FSOs, and MSOs. Thus, of the three groups, solo FSOs showed the highest levels of sexual dissatisfaction, depression, and substance abuse. A significant difference on the Offending history subscale between MSOs compared with both solo and co- FSOs showed that males were more likely to have a previous sexual offense, or previous non-violent/non-sexual convictions. Co- FSOs also scored significantly higher than MSOs across the Relationship factors, Family factors, and Proximal factors subscales suggesting that female co-offenders show more evidence of unstable relationships and previous exploitive and/or abusive relationships; unstable family life, family stressors (e.g., debts); predominantly pro-criminal social groups, and a possessive/violent partner, compared with MSOs.

Offense preceding factors. Scores among MSOs and solo FSOs were significantly higher than those for co- FSOs on the Personal factors subscale, indicating more negative mood states and a greater need for intimacy. Although the $F$ test indicated a significant effect of group on the Environmental factors subscale, post-hoc tests revealed no significant between group differences.

Positive factors. MSOs scored significantly higher than both solo and co- FSOs on the Personal Factors subscale, with MSOs showing more positive personal factors including an awareness of the consequences of their behavior, and demonstrating more remorse or empathy. A significant $F$ test also pointed toward differences between groups on the Treatment readiness subscale, however the results of post-hoc tests failed to highlight any significant differences. On the Treatment supportive subscale, co- FSOs differed significantly from both solo FSOs, and MSOs, scoring lower on items that indicated partner/family acceptance of treatment plan, and safe/supportive environment for change. 
Sexual abuse supportive cognitions subscale. Here we explored whether there were any significant differences between female solo offenders, female co-offenders, and MSOs, on the Sexual abuse supportive cognitions subscale of the Psychological dispositions scale. This subscale consists of several further subscales referring to child as sexual being, nature of harm, entitlement, dangerous world, uncontrollable, and other directedness sexual abuse supportive cognitions. The results of the analysis, along with means and $S D \mathrm{~s}$, are available in Table 4.

The MANOVA revealed a significant effect of group on Sexual abuse supportive cognitions $\left(\right.$ Pillai's Trace $\left.=.33, F(12,146)=2.428, p=.007, \mathrm{p}^{2}=.17\right)$. Post-hoc tests showed that MSOs and co- FSOs differed on the Entitlement subscale, with MSOs showing more distortions relating to the entitlement category (e.g., the child is mine/ownership over child, and own needs greater than victims) compared with co-offenders. Solo FSOs did not differ from either co- FSOs or MSOs on Entitlement. Thus, while MSOs and co- FSOs were statistically different to each other, solo FSOs did not differ statistically from either group. On the Dangerous world subscale (e.g., child easier/safer than adults, and mistrust/others will lie/manipulate me), MSOs and solo FSOs both scored higher than co- FSOs.

\section{INSERT TABLE 4 ABOUT HERE}

\section{Discussion}

Existing research on FSOs has compared the victim, offender, and offense characteristics of solo and co-offenders, while a more limited body of work has sought to compare the characteristics of FSOs and MSOs more broadly. However, very little work has compared the characteristics of female solo and female co-offenders, and MSOs. In this study we compared 20 solo FSOs, 20 co-FSOs, and 40 MSOs using an adapted version of The Framework (Gillespie et al., 2015). We found that female solo and co-offenders and MSOs differed from 
each other on a number of scales, including Psychological dispositions, Environmental niche factors, Offense preceding factors, and Positive factors. In addition, a further analysis showed that the three groups differed in their Sexual abuse supportive cognitions, with significant differences on the entitlement and dangerous world subscales.

There was some evidence for adverse developmental factors in each group but no significant differences between the three groups were observed. Both solo and co- FSOs, and MSOs, typically experience early abuse. However, the abusive experiences of FSOs have been reported as more severe and extensive than those of their male counterparts (Allen, 1991; West et al., 2011; Colson et al., 2013). Although the data reported here suggest that were no differences in the abusive experiences of the three groups, the items in The Framework do not code for the extensiveness or severity of this abuse. Nonetheless, our results suggest that solo and co-FSOs, and MSOs, may benefit from opportunities to explore and reflect in a therapeutic setting on experiences of victimization, and the impact that this has had.

On the psychological dispositions scale, we found significant differences on the interpersonal factors and the self-management/self-regulation subscales. The main differences on these subscales appeared to be between the male and female groupings, rather than between the female solo and co-offender groupings. We found that solo FSOs scored higher than MSOs for interpersonal factors, showing lower levels of self-esteem and assertiveness, and greater emotional loneliness. In contrast to our hypotheses, co- FSOs did not differ in interpersonal factors from either MSOs or solo FSOs. However, we did find differences between co- FSOs and MSOs on both the self-management/self-regulation subscale, and the sexual selfregulation subscale. Results suggested that while female co-offenders may experience more self-management difficulties, including greater impulsivity and poorer regulation of negative affect, MSOs show more problems in regulating their sexual thoughts and arousal. 
Previous research has highlighted the importance of interpersonal difficulties and selfregulatory deficits for both female (Gannon et al., 2008; Grayston \& De Luca, 1999; Nathan \& Ward, 2002), and male offenders (Gillespie, Mitchell, Fisher, \& Beech, 2012; Ward \& Beech, 2006). The results reported here extend upon these findings and point toward differences in the self-regulatory styles of FSOs and MSOs. Our results suggest that solo FSOs may require particular support in developing the skills and confidence to form mutual relationships with appropriate adults, as well as in developing self-esteem and assertiveness. On the other hand, co- FSOs appear to be better characterized by self-management and emotion regulation difficulties, at least when compared with MSOs. Co- FSOs may therefore benefit from treatment approaches that incorporate the development of adaptive coping strategies and self-soothing techniques, including the use of mindfulness techniques for improving emotion regulation (Gillespie et al., 2012).

MSOs showed a greater tendency than co- FSOs toward viewing children as ideal sexual partners, were reinforcing of children's sexual behaviours, and showed increased use of grooming techniques. The offending behaviors of MSOs therefore appear to be more sexually motivated, or driven by impaired abilities for sexual self-regulation. These findings may lend support to earlier results suggesting that the offending behaviors of co- FSOs, including victim choice, may better reflect the sexual interests of their male co-offending partner. For example, it has been shown that co- FSOs more often have a greater number of female victims compared with solo FSOs (Muskens et al., 2011; Vandiver, 2006; Wijkman et al., 2011). In contrast, the offending behaviors of solo FSOs and MSOs may be similarly motivated by the meeting of sexual needs through sex with children and young people.

We also found significant differences between groups with regard to the offenders' environmental niche, with solo FSOs more likely to have experienced mental health difficulties, and psychological vulnerabilities, compared with both co- FSOs and MSOs. The 
results are consistent with the findings of Muskens et al. (2011) who also found higher levels of psychopathology among solo compared with co- FSOs. Importantly, our results suggest that heightened reporting of extensive psychopathology among FSOs compared with MSOs (e.g., West et al., 2011; Miller et al., 2009) may be driven by solo rather than co- FSOs. This pattern of results suggests that monitoring of their mental stability, and psychological interventions aimed at developing insight and relapse prevention strategies surrounding mental health may prove useful for solo FSOs. Other findings from the environmental niche scale suggested that co- FSOs showed more difficulties compared with MSOs relating to family, relationships, and the local area in which they live. A more systemic approach to intervention with co- FSOs that includes work with family and close friends may therefore prove to be most effective.

The importance of internal versus external factors in distinguishing between FSOs and MSOs is highlighted further on the offense preceding factors and the positive factors scales. For example, relative to co- FSOs, the offense preceding factors of solo FSOs, and MSOs, were better characterized by low mood and a need for intimacy or power. These findings suggest more problematic internal factors among solo FSOs and MSOs immediately prior to the offense. In contrast, scores on the positive factors scales suggest a greater number of external difficulties among co- FSOs, including environmental and family difficulties that could limit the extent to which they are able to engage with and progress through treatment. Again, our results suggest that co- FSOs may benefit from a more systemic approach to their treatment that takes into account the social network. On the other hand, solo FSOs and MSOs may require more individual work focussed on the internal difficulties that precede their offending behaviours.

Scores on these subscales also indicated that MSOs showed more empathy and a greater understanding of the consequences of their offending compared with both solo and co- FSOs. 
However, MSOs may have had more opportunities for treatment relating to their offending behaviors, and the extent to which these scores reflect real differences between MSOs, and solo and co- FSOs, remains unclear. Alternatively, female offenders' limited understanding of the consequences of their offending may reflect an internalizing of society's minimization and lack of knowledge around female perpetrated sexual offenses (Giguere \& Bumby, 2007). Interventions that include psychoeducational components may therefore be effective in supporting FSOs to develop an understanding of how their behaviours can be considered as abusive. In support of this approach, benefits in affective and interpersonal functioning have recently been reported among male users of child sexual exploitation material after attending a community based psychoeducational group-work program (Gillespie, Bailey, Squire, Carey, Eldridge, \& Beech, 2016; Dervley, Perkins, Whitehead, Bailey, Gillespie, \& Squire, 2017). However, the benefits of such programs for FSOs remain to be seen.

It was also hypothesized that MSOs and solo and co- FSOs would differ in their sexual abuse supportive cognitions. Consistent with our hypothesis, MSOs scored higher than co- FSOs on entitlement, while MSOs and solo FSOs both scored higher than co- FSOs for cognitions relating to dangerous world. Although attitudes originally identified among MSOs have also been reported among FSOs, gender specific sexual abuse supportive cognitions nonetheless exist (Beech et al., 2009; Gannon et al., 2010). Furthermore, the gender specific content of females' cognitions is closely related to the presence of a co-offender, and includes favouring the needs of a partner over a victim, and viewing men as threatening (Gannon et al., 2010). The quantitative data gathered here differs in important methodological ways from the qualitative data analysed by Gannon et al. (2010), with case files analysed in this study not containing a focussed assessment of sexual abuse supportive cognitions. Such methodological variance should therefore be considered when drawing conclusions from these studies. 
The nature of The Framework means that the difficulties reported here should be considered to represent clinical, rather than 'criminogenic' needs, and we have not shown that these factors are predictive of sexual offense recidivism. Nonetheless, these difficulties represent examples of functional variables that may be relevant to sexually abusive behaviours, and although the recidivism rates of females are relatively low (Cortoni et al., 2010), and sex offender specific treatment may not be necessary, targeting these problems may contribute to successful rehabilitation. Based on the results here, we would suggest that treatment strategies for solo FSOs might focus on coping with difficult experiences and reducing psychological vulnerabilities, while input from mental health services could be considered following an assessment of psychopathology. Conversely, work with female co-offenders may benefit from a more systemic approach that considers the potential negative impact of the female's environment. Contact with positive support mechanisms may also help to overcome poor partner and family relationships.

\section{Limitations}

The results reported here should be interpreted in light of methodological limitations, including the fact that analyses were based on a total of 40 male and 40 female (20 solo and 20 co-offending) participants. Limited sample sizes are a common critique of FSO research (Oliver, 2007), and this issue can have a negative impact on both statistical power and observed effect sizes. As such, our findings should be interpreted with a degree of caution. It is also important to highlight that a selection bias was introduced in the selection of files based on practitioners' recall of previously assessed individuals. Additional files were also randomly selected, with decisions for inclusion guided by the inclusion criteria.

The data obtained were dependent on the quality and amount of information available in the case files. Although case files always included a clinical assessment and/or intervention 
report written by an LFF practitioner, and these were often accompanied by responses on a number of self-report measures, the quality of information nonetheless varied. Furthermore, these data may have been limited by participants' abilities for introspection, and to accurately report complex thoughts, feelings, motivations, and behaviors. The extent to which the participants provided biased or inaccurate responses during these clinical interviews could not be assessed.

Although one of the strengths of this study is the inclusion of separate groups of female solo and co-offenders for comparison with MSOs, future research should aim to further scrutinise subtypes of female and male sexual offenders. Further subtyping may be done on the basis of intra-familial versus extra-familial offending, and contact versus non-contact offending. Also, as highlighted by Wijkman et al. (2010), female co-offenders may be further categorised on the basis of having committed contact abuse themselves, or having viewed and/or allowed the abuse to happen. Accounting for these differences in offending behaviours will allow for a more nuanced understanding of the treatment needs of different female and male sexual offenders. Demographic information reported in Table 1 also suggests a relative absence of FSOs with a more general history of antisocial behaviour. Although previous work suggests that general antisociality may be a more prominent characteristic of MSOs (Freeman \& Sandler, 2008), a generally antisocial pathway to female sexual offending has nonetheless been suggested (Wijkman et al., 2011).

\section{Conclusions}

The results of the present study are consistent with earlier findings that suggest meaningful differences between FSOs and MSOs. The findings reported here contribute to existing knowledge by highlighting the ways in which MSOs may differ from both solo and co- FSOs on a variety of personal characteristics. These groups were found to differ in their 
psychological dispositions, environmental niche, and offense preceding factors. In particular, while female solo offenders showed heightened interpersonal difficulties and mental health problems compared with MSOs, female co-offenders showed more evidence of selfregulation difficulties. In contrast, MSOs were better characterized by sexual self-regulation problems and a history of general antisociality. The present study also represents one of the first attempts to examine the presence of various sexual abuse supportive cognitions between MSOs and solo and co-offending females. We showed that cognitions referring to 'entitlement' and 'dangerous world' were more often reported in the case files of MSOs compared with co-offending females. Our results have implications for the assessment and treatment of female solo and co-offenders, and the issue of co-offending may also be worthy of investigation among MSOs. Perhaps, most importantly, these results emphasize the importance of a gender specific approach to working with men and women who sexually abuse children.

\section{References}

Ahlmeyer, S., Kleinsasser, D., Stoner, J. \& Retzlaff, P. (2003). Psychopathology of Incarcerated Sex Offenders. Journal of Personality Disorders, 17, 306-318. doi:10.1521/pedi.17.4.306.23969

Allen, C. M. (1991). Women and men who sexually abuse children: A comparative analysis. Brandon, VT: The Safer Society Press.

American Psychiatric Association. (1994). Diagnostic and statistical manual of mental disorders (4th ed.). Washington, DC: Author.

Andrews, D. A., \& Bonta, J. (2010). The psychology of criminal conduct (5th Ed.). New Providence, NJ: LexisNexis Group. 
Beck, J. S. (1995). Cognitive therapy: Basics and beyond. New York: Guilford Press.

Beech, A. R., Parrett, N., Ward, T., \& Fisher, D. (2009). Assessing FSO’ motivations and cognitions: an exploratory study. Psychology, Crime, and Law, 15, 201-216. doi:10.1080/10683160802190921

Budd, K. M., Bierie, D. M. \& Williams, K. (2015). Deconstructing incidents of female perpetrated sex crimes: Comparing female sexual offender groupings. Sexual Abuse: A Journal of Research and Treatment. Published online before print. doi:10.1177/1079063215594376

Carr, A. (1999). The handbook of child and adolescent clinical psychology: a contextual approach. London: Routledge.

Colson, M. H., Boyer, L., Baumstarck, K., \& Loundou, A. D. (2013). Female sex offenders: A challenge to certain paradigms. Meta-analysis. Sexologies, 22, 109-117. doi:10.1016/j.sexol.2013.05.002

Cortoni, F. (2010). The assessment of female sexual offenders. In T. A. Gannon \& F. Cortoni (Eds.), Female sexual offenders: Theory, assessment and treatment (pp. 87-100). West Sussex, UK: John Wiley \& Sons Ltd.

Cortoni, F., Babchishin, K. M. \& Rat, C. (2017). The proportion of sexual offenders who are female is higher than thought. Criminal Justice \& Behavior, 44, 145-162. doi: $\underline{10.1177 / 0093854816658923}$

Dervley, R., Perkins, D., Whitehead, H., Bailey, A., Gillespie, S., \& Squire, T. (2017). Themes in participant feedback on a risk reduction programme for child sexual exploitation material offenders. Journal of Sexual Aggression, 23, 46-61. doi:10.1080/13552600.2016.1269958 
Elliott, I. A., Eldridge, H. J., Ashfield, S., \& Beech, A. R. (2010). Exploring risk: Potential static, dynamic, protective and treatment factors in the clinical histories of female sex offenders. Journal of Family Violence, 25, 595- 602. doi:10.1007/s10896-010$9322-8$

Ford, H. (2010). The treatment needs of female sexual offenders. In T. A. Gannon \& F. Cortoni (Eds.), Female sexual offenders: Theory, assessment and treatment (pp. 101-117). West Sussex, UK: John Wiley.

Freeman, N. J., \& Sandler, J. C. (2008). Female and male sex offenders: A comparison of recidivism patterns and risk factors. Journal of Interpersonal Violence, 23, 13941413. doi:10.1177/0886260508314304

Gannon, T. A. \& Cortoni F. (2010). Female sexual offenders: Theory, assessment and treatment- An introduction. In T. A. Gannon \& F. Cortoni (Eds.), Female sexual offenders: Theory, assessment and treatment (pp. 1-7). West Sussex, UK: John Wiley \& Sons Ltd.

Gannon, T. A., \& Alleyne, E. K. A. (2013). Female sexual abusers' cognition: A systematic review. Trauma, Violence and Abuse, 14, 67-79. doi:10.1177/1524838012462245

Gannon, T. A., Hoare, J. A., Rose, M. R., \& Parrett, N. (2010). A re-examination of female child molesters' implicit theories: evidence of female specificity? Psychology, Crime and Law, 18, 209-224. doi:10.1080/10683161003752303

Gannon, T. A., Rose, M. R. \& Cortoni, F. (2010). Developments in female sexual offending and considerations for future research and treatment. In T.A. Gannon \& F. Cortoni (Eds), Female sexual offenders: Theory, assessment and treatment (pp. 181-198). West Sussex, UK: John Wiley \& Sons Ltd. 
Gannon, T.A., Rose, M.R. \& Ward, T. (2008). A descriptive model of the offence process for female sexual offenders. Sexual Abuse: A Journal of Research and Treatment, 20, 352-374. doi:10.1177/1079063208322495

Giguere, R., \& Bumby, K. (2007). Female sex offenders. Silver Spring, Maryland: Center for Effective Public Policy, Center for Sex Offender Management. Retrieved from http://www.csom.org/pubs/female\%5Fsex\%5Foffenders\%5Fbrief.pdf

Gillespie, S. M., Bailey, A., Squire, T., Carey, M. L., Eldridge, H. J., \& Beech, A. R. (2016). An evaluation of a community-based psycho-educational program for users of child sexual exploitation material. Sexual Abuse: A journal of Research and Treatment. Published online before print. doi:10.1177/1079063216639591

Gillespie, S. M., Mitchell, I.J., Fisher, D. \& Beech, A.R. (2012). Treating disturbed emotional regulation in sexual offenders: The potential applications of mindful self-regulation and controlled breathing techniques. Aggression and Violent Behavior, 17, 333-343. doi:10.1016/j.avb.2012.03.005

Gillespie, S. M., Williams, R., Elliott, I. A., Eldridge, H. J., Ashfield, S. \& Beech, A. R. (2015). Characteristics of females who sexually offend: A comparison of solo and co-offenders. Sexual Abuse: A Journal of Research and Treatment, 27, 284-301. doi:10.1177/1079063214556358

Grayston, A. D. \& De Luca, R.V. (1999). Female perpetrators of child sexual abuse: A review of the clinical and empirical literature. Aggression and Violent Behavior, 4, 93-106. doi:10.1016/S1359-1789(98)00014-7

Greenberger, D., \& Padesky, C. A. (1995). Mind over mood: Change how you feel by changing the way you think. New York: Guilford Press. 
Langton, C. M. \& Marshall, W. L. (2001). Cognition in rapists: Theoretical patterns by typological breakdown. Aggression and Violent Behavior, 6, 499-518. doi:10.1016/S1359-1789(00)00029-X

Linehan, M. M. (1993). Cognitive-behavioral treatment of borderline personality disorder. New York: Guilford Press.

Mathews, R., Matthews, J., \& Speltz, K. (1989). FSO: An exploratory study. Brandon, Vermont: Safer Society Press.

Miller, H. A., Turner, T. \& Henderson, C. E. (2009). Psychopathology of sex offenders: A comparison of males and females using latent profile analysis. Criminal Justice and Behavior, 36, 778-793. doi:10.1177/0093854813509369

Muran, J. C., \& Segal, Z. V. (1992). The development of an idiographic measure of selfschemas: An illustration of the construction and use of self-scenarios. Psychotherapy, 29, 524-535.

Muskens, M., Bogaerts, S., Van Casteren, M. \& Labrijn, S. (2011). Adult female sexual offending: A comparison between co-offenders and solo offenders in a Dutch sample. Journal of Sexual Aggression, 17, 46-60.

doi:10.1080/13552600.2010.544414

Nathan, P., \& Ward, T. (2001). Females who sexually abuse children: Assessment and treatment issues. Psychiatry, Psychology and Law, 8, 44-45. doi:10.1080/13218710109525003

Persons, J. B. (1989). Cognitive therapy in practice: A case formulation approach. New York: Norton. 
Strickland, S. M. (2008). Female sex offenders: Exploring issues of personality, trauma, and cognitive distortions. Journal of Interpersonal Violence, 23, 474- 490. doi: $\underline{10.1177 / 0886260507312944}$

Turner, K., Miller, H. A. \& Henderson, C. E. (2008). Latent profile analyses of offence and personality characteristics in a sample of incarcerated FSO. Criminal Justice and Behavior, 35, 879-895. doi:10.1177/0093854808318922

Vandiver, D. M. (2006). Female sex offenders: A comparison of solo offenders and cooffenders. Violence and Victims, 21, 339- 354. doi:10.1891/vivi.21.3.339

Ward, T. (2000). Sexual offenders' cognitive distortions as implicit theories. Aggression and Violent Behavior, 5, 491-507. doi:10.1016/S1359-1789(98)00036-6

Ward, T., \& Beech, A. R. (2006). An integrated theory of sexual offending. Aggression and Violent Behavior, 11, 44-63. doi:10.1016/j.avb.2005.05.002

West, S. G., Hatters Friedman, S., \& Dan Kim, K. (2011). Women accused of sex offences: A gender-based comparison. Behavioral Sciences and the Law, 29, 728-740. doi:10.1002/bsl.1007

Wijkman, M., Bijleveld, C. \& Hendriks, J. (2010). Women don’t do such things! Characteristics of female sex offenders and offender types. Sexual Abuse: A Journal of Research and Treatment, 22, 135-156. doi:10.1177/1079063210363826

Wijkman, M., Bijleveld, C. \& Hendriks, J. (2011). Female sex offenders: Specialists, generalists and once-only offenders. Journal of Sexual Aggression, 17, 34- 45. $\underline{\text { doi: } 10.1080 / 13552600.2010 .540679}$

Williams, K. S. \& Bierie, D.M. (2015). An incident-based comparison of female and male sexual offenders. Sexual Abuse: A Journal of Research and Treatment, 27, 235- 257. doi:10.1177/1079063214544333 
Young, J. E. (1990). Cognitive therapy for personality disorders: A schema-focused approach. Sarasota, FL: Professional Resource Press.

\section{Acknowledgments}

The authors would like to thank Dr Michael Seto, Dr Franca Cortoni, and the anonymous reviewers for their helpful comments during the review process. The authors take responsibility for the integrity of the data, the accuracy of the data analyses, and have made every effort to avoid inflating statistically significant results.

\section{Funding}

The author(s) received no financial support for the research, authorship, and/or publication of this article.

\section{Declaration of financial interests}

The author(s) declared no potential conflicts of interest with respect to the research, authorship, and/or publication of this article. 
Table 1

Offender, offense and victim characteristics for solo and co-FSO, and MSO

\begin{tabular}{|c|c|c|c|}
\hline Variable & $\begin{array}{l}\text { Solo female } \\
\qquad(N=20)\end{array}$ & $\begin{array}{l}\text { Co female }(N \\
\quad=20) \\
\text { Mean }(\mathrm{SD})\end{array}$ & Male $(N=40)$ \\
\hline \multirow[t]{2}{*}{ Age } & $33.24(6.83)$ & $34.83(5.80)$ & $32.43(10.01)$ \\
\hline & \multicolumn{3}{|c|}{$\%$} \\
\hline \multicolumn{4}{|l|}{ Ethnicity } \\
\hline Caucasian & 55 & 45 & 48 \\
\hline Black & 0 & 0 & 5 \\
\hline Unknown & 45 & 55 & 48 \\
\hline \multicolumn{4}{|l|}{ Sentence } \\
\hline Custodial & 30 & 30 & 53 \\
\hline Community Order & 20 & 25 & 23 \\
\hline Suspended Sentence & 5 & 5 & 3 \\
\hline Awaiting Sentencing & 0 & 5 & 8 \\
\hline Caution & 0 & 0 & 5 \\
\hline Unknown & 45 & 35 & 10 \\
\hline \multicolumn{4}{|l|}{ Referral Service } \\
\hline Family Court & 45 & 65 & 90 \\
\hline Criminal Justice System & 55 & 35 & 8 \\
\hline GP & 0 & 0 & 3 \\
\hline \multicolumn{4}{|l|}{ Previous Convictions } \\
\hline Sexual & 5 & 5 & 23 \\
\hline Violent & 0 & 0 & 25 \\
\hline Acquisitive & 20 & 10 & 43 \\
\hline Drug-related & 20 & 0 & 8 \\
\hline \multicolumn{4}{|l|}{ Offense Type } \\
\hline Contact & 75 & 60 & 70 \\
\hline Non-contact & 15 & 40 & 30 \\
\hline \multicolumn{4}{|l|}{ Criminal Charge } \\
\hline Rape & - & 10 & 10 \\
\hline Gross indecency & - & 15 & 0 \\
\hline Indecent assault & 15 & 25 & 32.5 \\
\hline Buggery & 5 & - & 2.5 \\
\hline Unlawful sexual intercourse & - & 5 & 5 \\
\hline Sexual activity with a minor & 20 & 5 & 12.5 \\
\hline Incest & - & - & 2.5 \\
\hline Anal rape & - & - & 2.5 \\
\hline Sexual assault & 20 & 20 & 10 \\
\hline $\begin{array}{l}\text { Causing or inciting a person } \\
\text { below the age of } 16 \text { to engage } \\
\text { in sexual activity }\end{array}$ & 5 & 10 & 2.5 \\
\hline
\end{tabular}




\begin{tabular}{|c|c|c|c|}
\hline $\begin{array}{l}\text { Aiding and abetting sexual } \\
\text { assault }\end{array}$ & - & 15 & - \\
\hline Voyeurism & - & - & 2.5 \\
\hline Possession of obscene material & - & - & 7.5 \\
\hline Downloading indecent images & - & - & 2.5 \\
\hline $\begin{array}{l}\text { Causing a minor to watch } \\
\text { indecent images }\end{array}$ & - & - & 2.5 \\
\hline $\begin{array}{l}\text { Taking and distributing } \\
\text { indecent images }\end{array}$ & 10 & 25 & 15 \\
\hline Failure to protect & - & 30 & - \\
\hline Perverting the course of justice & - & 10 & - \\
\hline Abuse of position of trust & 5 & - & - \\
\hline $\begin{array}{l}\text { Meeting a child following } \\
\text { grooming }\end{array}$ & 5 & - & - \\
\hline \multicolumn{4}{|l|}{ Victim Age } \\
\hline Under 5 & 25 & 20 & 5 \\
\hline $6-12$ years & 15 & 50 & 43 \\
\hline 13 years and above & 60 & 25 & 40 \\
\hline Unknown & 0 & 5 & 13 \\
\hline \multicolumn{4}{|l|}{ Victim Relationship } \\
\hline Intra-familial & 40 & 85 & 27.5 \\
\hline Extra-familial & 60 & 15 & 47.5 \\
\hline Both & 0 & 0 & 12.5 \\
\hline Unknown & 0 & 0 & 12.5 \\
\hline \multicolumn{4}{|l|}{ Number of Victims } \\
\hline 1 & 80 & 50 & 42.5 \\
\hline 2 or more & 15 & 50 & 50 \\
\hline Unknown & 5 & 0 & 7.5 \\
\hline \multicolumn{4}{|l|}{ Co-offender Gender } \\
\hline Male & - & 85 & - \\
\hline Female & - & 5 & - \\
\hline Both & - & 5 & - \\
\hline \multicolumn{4}{|l|}{ Co-offender Relationship } \\
\hline Partner & - & 85 & - \\
\hline Known Acquaintance & - & 5 & - \\
\hline Stranger/ Unknown & - & 5 & - \\
\hline
\end{tabular}


Table 2

Intra-class Correlation Coefficients and 95\% Confidence Intervals for the five primary scales and the sexual abuse supportive cognitions subscale

\begin{tabular}{lcccc}
\hline & $\begin{array}{c}\text { Number of } \\
\text { items }\end{array}$ & ICC & \multicolumn{2}{c}{$\begin{array}{c}\text { 95\% Confidence } \\
\text { Interval }\end{array}$} \\
\cline { 3 - 5 } & 146 & .93 & .78 & .98 \\
\hline Whole scale & & & & Lower \\
$\begin{array}{l}\text { Subscales } \\
\text { Developmental factors }\end{array}$ & 23 & .99 & .99 & 1.00 \\
Psychological dispositions & 43 & .96 & .87 & .99 \\
Sexual abuse supportive & 21 & .90 & .71 & .97 \\
cognitions subscale & 28 & .94 & .81 & .98 \\
Environmental niche factors & 13 & .93 & .78 & .97 \\
Offence preceding factors & 39 & .98 & .93 & .99 \\
Positive factors & & & & \\
\hline
\end{tabular}


Table 3

Mean scores and standard deviations (SD) for solo and co-female offenders, and male

offenders, on each scale/subscale, complete with statistical detail from MANOVA.

\begin{tabular}{|c|c|c|c|c|c|c|}
\hline \multirow[t]{2}{*}{$\begin{array}{l}\text { Scale (number of } \\
\text { items) }\end{array}$} & $\begin{array}{l}\text { Solo female } \\
\qquad(N=20)\end{array}$ & $\begin{array}{l}\text { Co female } \\
(N=20)\end{array}$ & $\begin{array}{l}\text { Male }(N= \\
\quad 40)\end{array}$ & \multirow[t]{2}{*}{$F$} & \multirow[t]{2}{*}{$p$} & \multirow[t]{2}{*}{$\mathrm{p} \eta^{2}$} \\
\hline & \multicolumn{3}{|c|}{ Mean (SD) } & & & \\
\hline Developmental (23) & $4.45(4.56)$ & $5.10(3.99)$ & $4.55(3.67)$ & & & \\
\hline $\begin{array}{l}\text { Parental relationships } \\
\text { (4) }\end{array}$ & $1.50(1.61)$ & $1.85(1.63)$ & $1.97(1.33)$ & .69 & .50 & .02 \\
\hline $\begin{array}{l}\text { Childhood } \\
\text { environment (4) }\end{array}$ & $.95(1.05)$ & $1.00(1.08)$ & $.98(1.27)$ & .01 & .99 & .00 \\
\hline Emotional abuse (3) & $.60(.82)$ & $.75(.79)$ & $.72(.82)$ & .21 & .21 & .01 \\
\hline Violent abuse (3) & $.25(.55)$ & $.30(.47)$ & $.32(.57)$ & .13 & .13 & .003 \\
\hline Sexual abuse (4) & $.65(.99)$ & $.35(.67)$ & $.20(.41)$ & 3.10 & .05 & .08 \\
\hline $\begin{array}{l}\text { Other developmental } \\
\text { (5) }\end{array}$ & $.50(.83)$ & $.85(.99)$ & $.35(.53)$ & 3.01 & .06 & .07 \\
\hline $\begin{array}{l}\text { Psychological } \\
\text { dispositions (43) }\end{array}$ & $18.20(6.80)$ & $\begin{array}{l}15.10 \\
(7.20)\end{array}$ & $\begin{array}{l}16.88 \\
(6.50)\end{array}$ & & & \\
\hline $\begin{array}{l}\text { Interpersonal factors } \\
\text { (6) }\end{array}$ & $4.25(1.25)^{\mathrm{a}}$ & $\begin{array}{c}3.70 \\
(1.34)^{\mathrm{ab}}\end{array}$ & $3.05(1.58)^{\mathrm{b}}$ & 4.79 & 0.01 & .11 \\
\hline sexual abuse & & & & & & \\
\hline $\begin{array}{l}\text { supportive cognitions } \\
(21)\end{array}$ & $7.85(4.46)$ & $5.95(4.30)$ & $7.50(3.48)$ & 1.39 & .26 & .04 \\
\hline $\begin{array}{l}\text { Self-management/ } \\
\text { regulation (6) }\end{array}$ & $2.60(1.31)^{\mathrm{ab}}$ & $3.15(.75)^{\mathrm{a}}$ & $2.22(1.33)^{b}$ & 3.93 & 0.02 & .09 \\
\hline $\begin{array}{l}\text { Sexual self-regulation } \\
\text { (10) }\end{array}$ & $3.50(2.31)^{\mathrm{ab}}$ & $2.30(2.56)^{\mathrm{a}}$ & $4.1(1.97)^{\mathrm{b}}$ & 4.41 & .02 & .10 \\
\hline $\begin{array}{l}\text { Environmental niche } \\
\text { factors (28) }\end{array}$ & $10.80(3.86)$ & $\begin{array}{l}11.30 \\
(2.98)\end{array}$ & $8.88(3.67)$ & & & \\
\hline Personal (distal) (6) & $3.30(.98)^{\mathrm{a}}$ & $2.10(1.25)^{\mathrm{b}}$ & $2.48(1.36)^{\mathrm{b}}$ & 4.95 & .01 & .11 \\
\hline Offending history (3) & $.40(.60)^{\mathrm{a}}$ & $.20(.41)^{\mathrm{a}}$ & $.95(.93)^{\mathrm{b}}$ & 7.76 & .001 & .17 \\
\hline $\begin{array}{l}\text { Relationship factors } \\
\text { [distal] (4) }\end{array}$ & $2.40(.94)^{\mathrm{ab}}$ & $2.80(.62)^{\mathrm{a}}$ & $2.05(1.06)^{\mathrm{b}}$ & 4.34 & .02 & .10 \\
\hline $\begin{array}{l}\text { Family factors [distal] } \\
\text { (5) }\end{array}$ & $3.05(1.47)^{\mathrm{ab}}$ & $3.80(.20)^{\mathrm{a}}$ & $2.50(1.26)^{\mathrm{b}}$ & 6.73 & .002 & .15 \\
\hline Proximal factors (9) & $1.65(1.46)^{\mathrm{ab}}$ & $2.40(1.70)^{\mathrm{a}}$ & $.90(.78)^{b}$ & 10.01 & $<.001$ & .21 \\
\hline $\begin{array}{l}\text { Offence preceding } \\
\text { factors (13) }\end{array}$ & $5.05(1.70)$ & $3.66(2.52)$ & $4.93(1.97)$ & & & \\
\hline Personal (9) & $4.05(1.64)^{\mathrm{a}}$ & $2.05(1.93)^{\mathrm{b}}$ & $3.95(1.66)^{\mathrm{a}}$ & 9.42 & $<.001$ & .20 \\
\hline Environmental (4) & $1.00(.46)$ & $1.60(1.19)$ & $.98(.70)$ & 4.42 & .015 & .10 \\
\hline Positive factors (39) & $17.1(8.53)$ & $15.4(9.09)$ & $\begin{array}{c}24.30 \\
(10.15)\end{array}$ & & & \\
\hline Personal (17) & $6.00(3.78)^{\mathrm{a}}$ & $5.80(3.78)^{\mathrm{a}}$ & $\begin{array}{c}10.65 \\
(4.68)^{b}\end{array}$ & 12.44 & $<.001$ & .24 \\
\hline Contextual (14) & $6.20(3.62)$ & $5.65(3.95)$ & $7.95(4.49)$ & 2.46 & .09 & .06 \\
\hline
\end{tabular}




\begin{tabular}{|c|c|c|c|c|c|c|}
\hline $\begin{array}{l}\text { Treatment readiness } \\
\text { (3) }\end{array}$ & $1.35(1.09)$ & $1.50(1.05)$ & $2.03(.92)$ & 3.74 & 0.03 & .09 \\
\hline $\begin{array}{l}\text { Treatment supportive } \\
\text { factors }(5)\end{array}$ & $3.55(1.23)^{\mathrm{a}}$ & $2.45(1.50)^{b}$ & $3.68(1.59)^{\mathrm{a}}$ & 4.79 & .01 & .11 \\
\hline
\end{tabular}

Note: $\mathrm{p} \eta^{2}=$ partial-eta squared. Superscript letters denote results of Games-Howell post-hoc

tests. Values with different superscript letters are significantly different. Values that share a letter are statistically similar. 
Table 4

Means scores and standard deviations (SD) for solo and co-female offenders, and male offenders, on each subscale of the Sexual abuse supportive cognitions scale

\begin{tabular}{lcccccc}
\hline $\begin{array}{c}\text { Subscale (number of } \\
\text { items) }\end{array}$ & $\begin{array}{c}\text { Solo } \\
\text { female }(N \\
=20)\end{array}$ & $\begin{array}{c}\text { Co-female } \\
(N=20)\end{array}$ & $\begin{array}{c}\text { Male } \\
(N=40)\end{array}$ & $F$ & $p$ & $\mathrm{p \eta}^{2}$ \\
\cline { 2 - 5 } & \multicolumn{5}{c}{ Mean $(S D)$} \\
\hline Children as sexual & $1.70(1.46)$ & $1.15(1.31)$ & $1.58(1.22)$ & 1.03 & .36 & .03 \\
beings (3) & $1.60(1.39)$ & $1.40(1.47)$ & $1.73(1.13)$ & .43 & .65 & .01 \\
Nature of harm (4) & $.90(1.07)^{\mathrm{ab}}$ & $.50(.76)^{\mathrm{a}}$ & $1.3(1.04)^{\mathrm{b}}$ & 4.51 & .01 & .11 \\
Entitlement (4) & $.50(.61)^{\mathrm{a}}$ & $.10(.31)^{\mathrm{b}}$ & $.75(.74)^{\mathrm{a}}$ & 7.18 & .001 & .16 \\
Dangerous world (2) & $1.20(.83)$ & $1.10(.85)$ & $.80(.79)$ & 1.91 & .16 & .05 \\
Uncontrollable (3) & $1.95(1.43)$ & $1.70(1.49)$ & $1.35(1.53)$ & 1.15 & .32 & .03 \\
$\begin{array}{l}\text { Other directedness } \\
(5)\end{array}$ & &
\end{tabular}

Note: $\mathrm{p}^{2}=$ partial-eta squared. Superscript letters denote results of Games-Howell post hoc tests. Values with different superscript letters are significantly different. Values that share a letter are statistically similar. 